\title{
Characterization and Computational Modeling of Minor Phases in Alloy LSHR
}

\author{
Herng-Jeng Jou ${ }^{1}$, Gregory Olson ${ }^{1,2}$, Tim Gabb ${ }^{3}$, Anita Garg ${ }^{4}$, Derek Miller ${ }^{5}$ \\ ${ }^{1}$ QuesTek Innovations LLC, Evanston IL 60201 USA \\ ${ }^{2}$ Northwestern University, Evanston IL 60208 USA \\ ${ }^{3}$ NASA Glenn Research Center, Cleveland OH 44135 USA \\ ${ }^{4}$ University of Toledo, Toledo, OH 43606 USA \\ ${ }^{5}$ The Ohio State University, Columbus, OH 43210 USA
}

Keywords: Nickel-Base Superalloys, Carbide, Boride, Sigma, CALPHAD, Precipitation, Modeling, ICME

\begin{abstract}
The minor phases of powder metallurgy disk superalloy LSHR were studied. Samples were consistently heat treated at three different temperatures for long times to approach equilibrium. Additional heat treatments were also performed for shorter times, to assess minor phase kinetics in non-equilibrium conditions. Minor phases including $\mathrm{MC}$ carbides, $\mathrm{M}_{23} \mathrm{C}_{6}$ carbides, $\mathrm{M}_{3} \mathrm{~B}_{2}$ borides, and sigma were identified. Their average sizes and total area fractions were determined. CALPHAD thermodynamics databases and PrecipiCalc ${ }^{\circledR}$, a computational precipitation modeling tool, were employed with Ni-base thermodynamics and diffusion databases to model and simulate the phase microstructural evolution observed in the experiments with an objective to identify the model limitations and the directions of model enhancement.
\end{abstract}

\section{Introduction}

Structure, composition, fractions, and size distributions of carbide and boride phases can significantly influence the processing and mechanical properties of nickel-base superalloys [1-6], especially at elevated temperatures. MC carbides are stable up to very high temperatures near superalloy solidification, and therefore can help constrain grain growth during solution heat treatments above the gamma prime $\left(\gamma^{\prime}\right)$ solvus [7]. The elements $\mathrm{Ta}, \mathrm{Ti}, \mathrm{Nb}$, and $\mathrm{W}$ often combine with carbon to form this carbide. $\mathrm{M}_{23} \mathrm{C}_{6}$ carbides are stable at lower temperatures up to near $900^{\circ} \mathrm{C}$, and can improve the resistance to grain boundary sliding, rupture and dwell crack growth at service temperatures of $600-815^{\circ} \mathrm{C}$. Cr, $\mathrm{Mo}$, and $\mathrm{W}$ can react with carbon to form this carbide. Boron in solid solution within the $\gamma$ matrix also improves the resistance to grain boundary sliding, rupture, and dwell crack growth [5]. The $\mathrm{M}_{3} \mathrm{~B}_{2}$ boride phase has not been widely shown to specifically impact mechanical properties, but is often observed in disk superalloys containing boron. This phase can have a solidus temperature only slightly higher than solution heat treatment temperatures [6], and therefore can limit solution heat treatment upper tolerance temperatures. $\mathrm{Mo}, \mathrm{Cr}$, and $\mathrm{W}$ often combine with $\mathrm{B}$ to form this phase.

Harmful topological close packed (TCP) phases can also form in disk superalloys [1,2]. These phases such as $\sigma, \mu$, Laves, and P have low inherent ductility due to limited slip systems and often have needle or lath morphologies, and can sometimes reduce tensile and rupture ductilities at application temperatures $[8,9]$. Several models have been developed over the years to predict the formation of such phases [10,11].

Recent advances in multi-component thermodynamic modeling, based on CALculation of PHAse Diagrams (CALPHAD) $[12,13]$ framework, have resulted in software packages such as ThermoCalc [14], JMatPro [15] and PANDAT [16]. When used in conjunction with Ni-base databases, these software tools can be used for the prediction of relative percentages and compositions of phases of Ni-base superalloys in equilibrium at various temperatures. Further development of CALPHAD-based precipitation kinetics modeling has extended the capability to predict the transient precipitation microstructure with software tools such as PrecipiCalc [17,18], JMatPro [15], PanPrecipitation [16] and TC-PRISMA [19]. Model calibration and validation of CALPHAD databases and models with experimentally measured quantities $[18,20]$ is an integral part of integrated computational materials engineering (ICME) discipline [21].

In the first half of this article, measured minor phase identities, fractions (contents) and sizes in disk superalloy LSHR are reported after known heat treatments. In the second half, the results of CALPHAD-based equilibrium predictions made using several multicomponent thermodynamics databases and PrecipiCalc precipitation simulation are presented. The primary objective of this work was to determine the predominant minor phases in the disk superalloy LSHR after varied heat treatments, and to assess existing model capabilities and limitations for predicting these minor phases.

\section{Experimental Characterization of Minor Phases}

Disk superalloy LSHR having a composition in weight percent of $3.46 \mathrm{Al}, 0.028 \mathrm{~B}, 0.029 \mathrm{C}, 20.7 \mathrm{Co}, 12.52 \mathrm{Cr}, 0.07 \mathrm{Fe}, 2.73 \mathrm{Mo}$, $1.45 \mathrm{Nb}, 0.0188 \mathrm{O}, 0.0014 \mathrm{~N}, 0.03 \mathrm{Si}, 1.6 \mathrm{Ta}, 3.50 \mathrm{Ti}, 4.33 \mathrm{~W}$, $0.049 \mathrm{Zr}$, bal. $\mathrm{Ni}$ and trace impurities was produced through powder processing. It was atomized in argon, hot compacted, extruded and then isothermally forged into a flat, uniform disk $5.08 \mathrm{~cm}$ thick and $30.48 \mathrm{~cm}$ in diameter.

Phase extraction samples were removed by electro-discharge machining pins of about $10 \mathrm{~g}$ weight and $10 \mathrm{~mm}$ diameter in the circumferential direction from the rim of the disk. These samples were solution heat treated at $1199^{\circ} \mathrm{C}$ for $1 \mathrm{~h}$ and furnace cooled at an average rate of $21{ }^{\circ} \mathrm{C} / \mathrm{min}$. They were then aged at $843{ }^{\circ} \mathrm{C}$ for $1,000 \mathrm{~h}$ and water quenched. Electrochemical extractions of minor phase were performed using a $10 \mathrm{ml} \mathrm{HCl}-1 \mathrm{~g}$ tartaric acid$90 \mathrm{ml}$ methanol electrolyte. Triplicate extractions were performed in each case. Extracted phases and lattice parameters were identified using x-ray diffraction (XRD) [22].

Smaller pins of $3 \mathrm{~mm}$ diameter and $16 \mathrm{~mm}$ length were also machined in the circumferential direction near the rim of the disk, for performing various assessments. Samples were extracted from the extrusion before forging, and from the forging, for examination without further material processing. Heat treatment 
conditions of the remaining samples are summarized in Table 1 . Single samples were only solution heat treated at $1199^{\circ} \mathrm{C}$ for $1 \mathrm{~h}$, then water quenched at an average cooling rate of $5,000{ }^{\circ} \mathrm{C} / \mathrm{min}$. or furnace cooled at a controlled average cooling rate of 21 ${ }^{\circ} \mathrm{C} / \mathrm{min}$. Additional samples were solution heat treated at $1199{ }^{\circ} \mathrm{C}$ for $1 \mathrm{~h}$, water quenched at an average cooling rate of about 5,000 ${ }^{\circ} \mathrm{C} / \mathrm{min}$ to minimize phase nucleation and growth during the cooling process, and subsequently given aging heat treatments. They were aged at temperatures of 760,843 , and $927^{\circ} \mathrm{C}$ for times of 10,100 , and $1,000 \mathrm{~h}$ and again water quenched, yielding nine different aged cases.

Table 1. Heat Treatment Conditions.

\begin{tabular}{|c|c|c|c|c|}
\hline & $\begin{array}{c}1199 \mathrm{C} / \\
1 \mathrm{~h} / \\
\text { Solution } \\
\text { Quench }\end{array}$ & $\begin{array}{c}\text { Aging } \\
\text { Temp } \\
-\mathrm{C}\end{array}$ & $\begin{array}{c}\text { Aging } \\
\text { Time - } \\
\mathrm{h}\end{array}$ & $\begin{array}{c}\text { Aging } \\
\text { Quench }\end{array}$ \\
\hline LAF-Forged & & & & \\
\hline LFF & Furnace & & & \\
\hline LFW & Water & & & \\
\hline LFW760-10 & Water & 760 & 10 & Water \\
\hline LFW760-100 & Water & 760 & 100 & Water \\
\hline LFW760-1k & Water & 760 & 1000 & Water \\
\hline LFW843-10 & Water & 843 & 10 & Water \\
\hline LFW843-100 & Water & 843 & 100 & Water \\
\hline LFW843-1k & Water & 843 & 1000 & Water \\
\hline LFW927-10 & Water & 927 & 10 & Water \\
\hline LFW927-99 & Water & 927 & 99 & Water \\
\hline LFW927-1k & Water & 927 & 1000 & Water \\
\hline
\end{tabular}

Selected heat treated and quenched samples were sectioned and conventionally metallographically prepared. The sections were etched using a waterless Kallings etch. Linear intercept grain size was measured from optical images according to ASTM E112. SEM evaluations were used to select samples for determination of minor phase compositions using TEM and microprobe. Thin disks of $3 \mathrm{~mm}$ diameter and $\sim 0.5 \mathrm{~mm}$ thick were sliced, mechanically ground, and polished from selected heat-treated samples. These disks were then electrochemically thinned to electron transparency using a solution of $10 \%$ Perchloric and 90 $\%$ Methanol cooled to $-30{ }^{\circ} \mathrm{C}$. A FEI CM200 Transmission Electron Microscope (TEM) operating at $200 \mathrm{kV}$ was used for imaging and to identify crystal structure of predominant minor phases using selected area electron diffraction patterns (SAEDP) and energy dispersive X-ray spectroscopy (EDS). Associated bright field images were used to estimate the typical size range and morphology of each phase. Sections having larger size minor phase particles were usually selected for estimation of minor phase compositions using a JEOL JXA-8200 scanning electron microprobe. At least 5 particles of each minor phase were analyzed.

Sizes and area fractions of various second phases were quantified via SEM using metallographically prepared sections, in order to sample sufficient areas. Samples were imaged in a Hitachi S4700 Field Emission SEM at $20 \mathrm{kV}$ using a working distance of $12 \mathrm{~mm}$. Secondary electron and backscattered electron images were obtained at 2,000 x magnification, in order to include 4-8 grains and their associated boundaries within each image. This enabled statistically valid area fraction estimates for each phase in each image, even for phases such as $\mathrm{M}_{23} \mathrm{C}_{6}$ observed only at grain boundaries. Five adjacent images were acquired for each sample, with no bias of imaging towards a certain region of particles or grain boundaries. An EDAX CDU LEAP ${ }^{\mathrm{TM}}$ detector in the SEM was used for semi- quantitative chemical analysis of each particle visible in these images. Compositions determined from EDS spectra were then compared to results previously obtained in thin foil TEM evaluations. While the EDS spectra acquired using TEM and SEM were not identical, due to different interrogated volumes and instrumental conditions, relative major elemental compositions for a given phase were consistent for both cases. Based on theses analyses, the phase identity of each particle was recorded in the SEM images, and later used for size determinations of various phases. The combination of these two techniques enabled discrimination and measurement of minor phase contents and particle sizes over a much larger imaged area than what was feasible using TEM.

Particle sizes were measured using Sigma Scan Pro 5.0 image analysis software. The difference in brightness between minor and $\gamma-\gamma$ ' phases in secondary electron SEM images enabled brightness-based local thresholding. Each minor phase was measured separately, and also classified by location, either within grains or at grain boundaries. Area, equivalent radius, major axis, minor axis, and perimeter were determined for each particle. The equivalent radius calculation assumed a spherical shape and used the formula:

\section{Equivalent Radius $=\sqrt{\text { Area } / \pi}$}

Phase area fraction was determined by combining the areas of all particles of an identity and class within an image. Size-frequency histograms were generated for each phase with more than 10 particles acquired.

\section{Results and Discussion}

Heat Treatments

A typical SEM image of a sample extracted from the forging is shown in Figure 1. Linear intercept grain size of this sample was $5.5 \mu \mathrm{m}$. The large dark phase particles are primary $\gamma^{\prime}$, with mean radius of about $1.1 \mu \mathrm{m}$. These particles acted to constrain grain growth during extrusion and forging. Samples subsequently solution heat treated at $1199{ }^{\circ} \mathrm{C}$ for $1 \mathrm{~h}$ then furnace cooled and water quenched are shown in Figures 2 and 3. The primary $\gamma^{\prime}$ particles have dissolved during this solution treatment. These supersolvus solution heat treatments therefore allowed grain growth to a larger linear intercept grain size near $25 \mu \mathrm{m}$. Only $\mathrm{MC}$ carbides and $\mathrm{M}_{3} \mathrm{~B}_{2}$ borides were identified in these samples.

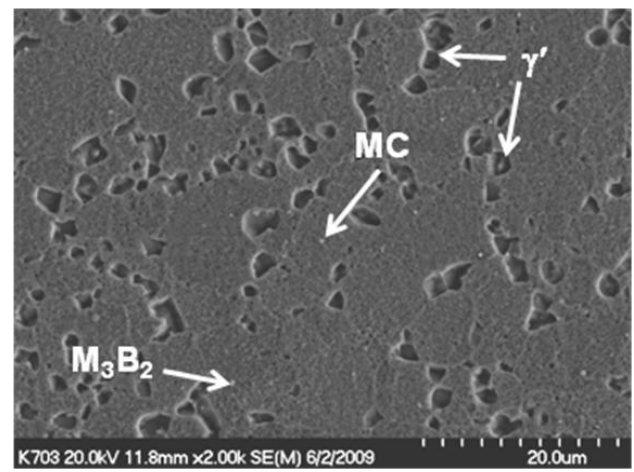

Figure 1. Image of LAF, as-forged sample. 


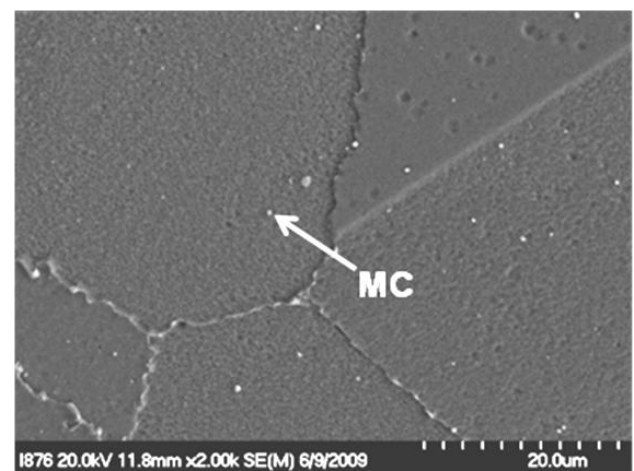

Figure 2. Image of LFF, forged sample solution heat treated $1199^{\circ} \mathrm{C} / 1 \mathrm{~h} /$ furnace cooled.

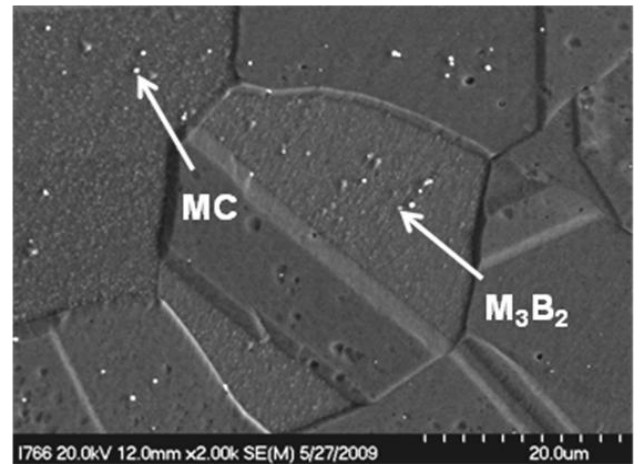

Figure 3. Image of LFW, forged sample solution heat treated $1199^{\circ} \mathrm{C} / 1 \mathrm{~h} /$ water quenched.

Images of samples aged $1,000 \mathrm{~h}$ at 760,843 , and $927{ }^{\circ} \mathrm{C}$ are compared in Figures 4, 5, and 6, respectively. $\mathrm{MC}$ and $\mathrm{M}_{23} \mathrm{C}_{6}$ carbides, $\mathrm{M}_{3} \mathrm{~B}_{2}$ borides, and sigma $(\sigma)$ phases were identified in these conditions [16]. These phases were also identified in samples aged shorter times of 10 and $100 \mathrm{~h}$ at 760,843 , and 927 ${ }^{\circ} \mathrm{C}$.

Subsequent measurements of minor phase sizes over multiple SEM images indicated the equivalent radius of each minor phase could be considered normally distributed, so that size distributions could be represented using mean and standard deviation for each phase.

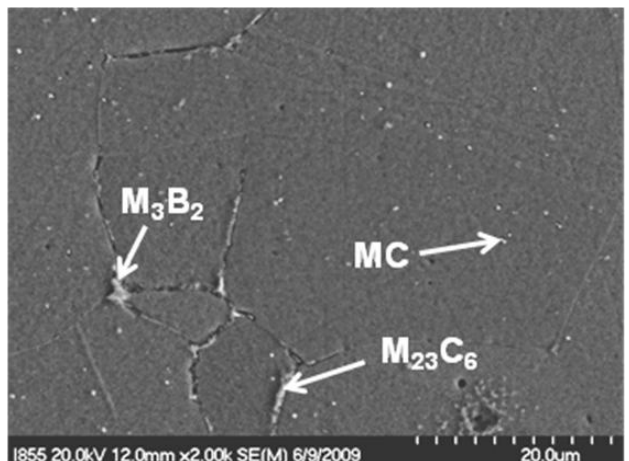

Figure 4. Image of LFW760-1k, forged sample solution heat treated $1199^{\circ} \mathrm{C} / 1 \mathrm{~h} /$ water quenched, aged $760{ }^{\circ} \mathrm{C} / 1,000 \mathrm{~h}$.

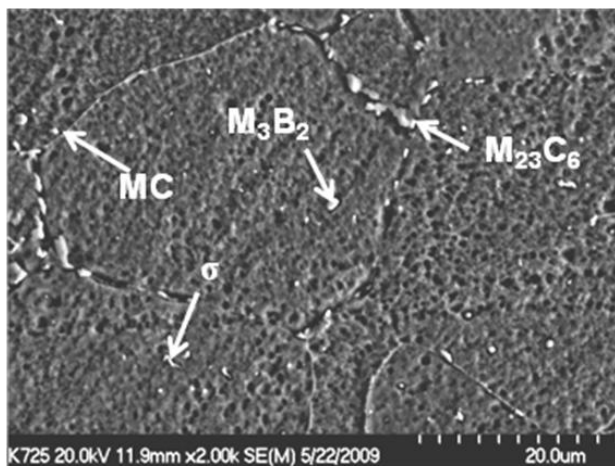

Figure 5. Image of LFW843-1k, forged sample solution heat treated $1199{ }^{\circ} \mathrm{C} / 1 \mathrm{~h} /$ water quenched, aged $843^{\circ} \mathrm{C} / 1,000 \mathrm{~h}$.

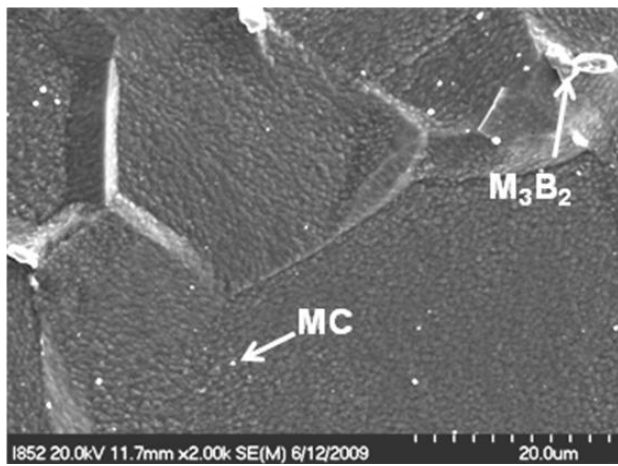

Figure 6. Image of LFW927-1k, forged sample solution heat treated $1199{ }^{\circ} \mathrm{C} / 1 \mathrm{~h} /$ water quenched, aged $927^{\circ} \mathrm{C} / 1,000 \mathrm{~h}$.

\section{$\underline{\mathrm{MC} \text { Carbides }}$}

MC carbides had an FCC Fm3m crystal structure, with a lattice parameter of $\mathrm{a}=4.3820$ angstroms $(\AA)$ measured with $\mathrm{XRD}$. This was comparable to that reported for several other disk superalloys [23], but slightly higher than that reported for Rene 88DT, an alloy somewhat similar in composition to LSHR [24]. MC carbide average equivalent radius did not exceed $0.27 \mu \mathrm{m}$ (Figures 1-3), making quantitative microprobe measurements of composition difficult. However, EDS measurements of these carbides in TEM thin foils indicated this phase had an approximate composition of $26 \mathrm{Ti}-12 \mathrm{Nb}-12 \mathrm{Ta}-50 \mathrm{C}$ in atomic percent, Table 3. Quantitative compositions are not often reported for minor phases such as carbides and borides existing at such small sizes, due to difficulties of in-situ measurements using scanning electron microscopy. However, surveys indicate many other disk superalloys also have MC carbides which contain $\mathrm{Ti}$, $\mathrm{Ta}$, and $\mathrm{Nb}[1,2,23,24]$. The slightly higher lattice parameter compared to Rene 88DT could be related to the presence of Ta in MC carbides for LSHR. Overall MC carbide size, morphology, and area fraction appeared comparable in most samples, indicating high overall phase stability for the various conditions examined. While most appeared spherical or slightly elliptical in the SEM images presented, TEM examinations indicated the MC carbides usually had short cylindrical or blocky shapes, each made up of a single crystal.

Yet, some changes in MC carbides were observed when comparing those within grains versus at grain boundaries. About $35 \%$ of the carbides were observed at grain boundaries after forging, Figure 1. However, no more than $23 \%$ were observed at 
grain boundaries for samples subsequently water quenched and aged, Figures 2-3 and Table 2. Here they more often appeared within the grains, sometimes loosely distributed in clusters. Additional systematic evaluations at lower magnifications would be necessary to fully quantify the degree of clustering in their spatial distribution. The MC carbides at grain boundaries were often slightly larger than those within grains. MC carbide content at grain boundaries decreased with increasing aging time at 843 ${ }^{\circ} \mathrm{C}$, which will be further considered below.

\section{$\underline{\mathrm{M}_{23}} \underline{\mathrm{C}_{6}}$ Carbides}

$\mathrm{M}_{23} \mathrm{C}_{6}$ carbides had an FCC Fm3m crystal structure, with lattice parameter estimated using TEM of $10.6 \AA$. This is very close to that reported for Rene 88DT [24]. The average phase composition was measured by microprobe on a sample aged 843 ${ }^{\circ} \mathrm{C} / 1,000 \mathrm{~h}$, having particles sometimes as large as $0.5 \mu \mathrm{m}$ radius, Fig. 4. Microprobe quantitative measurements indicated this phase had an approximate composition of $33.0 \mathrm{Cr}-20.6 \mathrm{Co}-14.3 \mathrm{Ni}-$ $5.4 \mathrm{Mo}-2.5 \mathrm{~W}-24.2 \mathrm{C}$ in atomic percent, Table 2 . Surveys indicate other disk superalloys also have $\mathrm{M}_{23} \mathrm{C}_{6}$ carbides which are principally high in $\mathrm{Cr}$ and $\mathrm{Mo}[1,2,23,24]$. The high $\mathrm{Co}$ and $\mathrm{Ni}$ content measured here implies these elements can substitute for $\mathrm{Cr}$ in LSHR. The $\mathrm{M}_{23} \mathrm{C}_{6}$ carbides populated this alloy as particles often elongated along the grain boundaries. However, larger particles sometimes resided at triple points. TEM evaluations indicated the elongated particles were often made up of multiple grains. These carbides were not found away from grain boundaries. While some of these particles were highly elongated, equivalent radius was calculated to enable consistent comparisons among all particles and minor phases in this study.

Mean equivalent radius and area fraction of $\mathrm{M}_{23} \mathrm{C}_{6}$ carbides are shown versus sample condition in Table 2 . These carbides were not found in any samples that were not given aging heat treatments. This indicates that significant time is required at the aging temperatures for carbide formation to occur, exclusively at grain boundaries. Results show consistent trends in growth and dissolution for the different times and temperatures investigated. At both $760{ }^{\circ} \mathrm{C}$ and $843{ }^{\circ} \mathrm{C}$, the average equivalent radius and area fraction both increase with time. This trend was enhanced at 843 ${ }^{\circ} \mathrm{C}$, where the longest aging time of $1,000 \mathrm{~h}$ produced highest phase area fraction of 0.0042 and equivalent mean radius of near $0.29 \mu \mathrm{m}$ for this phase. Coarsening occurred at this temperature beyond $100 \mathrm{~h}$, where number density decreased while particle radius increased. Recall from Table 2 that MC carbide content at grain boundaries decreased with increasing time at $843{ }^{\circ} \mathrm{C}$. No MC carbides partially transformed in-situ to $\mathrm{M}_{23} \mathrm{C}_{6}$ carbides were directly observed for these samples, as previously reported for several other nickel-base superalloys $[1,2]$. Due to the difficulties in isolating such particles in SEM of metallographic sections and TEM of thin foils, this transformation could still be possible here. Based on the much wider spacing of prior MC carbides compared to that of $\mathrm{M}_{23} \mathrm{C}_{6}$, it appears that nucleation and growth of new particles accounted for a large majority of $\mathrm{M}_{23} \mathrm{C}_{6}$ phase particles observed in aged specimens. No $\mathrm{M}_{23} \mathrm{C}_{6}$ carbides were observed within grains in all aged conditions, and many $\mathrm{MC}$ carbides were still present there. At $927{ }^{\circ} \mathrm{C}, \mathrm{M}_{23} \mathrm{C}_{6}$ was found after $10 \mathrm{~h}$ aging, but not for longer times, indicating it is not stable at this temperature. Thus as the aging time increased and conditions approached equilibrium, the size and area fraction were driven to zero.

$\underline{\mathrm{M}}_{3} \underline{\mathrm{B}}_{2}$ Borides

$\mathrm{M}_{3} \mathrm{~B}_{2}$ borides had a tetragonal $\mathrm{P} 4 / \mathrm{mbm}$ crystal structure, with lattice parameters estimated as $a=5.791 \AA, b=3.150 \AA$ measured with XRD. These lattice parameters are comparable to those reported for this boride in other disk alloys [23, 24]. EDS and microprobe measurements on a sample aged $927{ }^{\circ} \mathrm{C}$ for $1,000 \mathrm{~h}$ (Figure. 5) indicated this phase had an approximate composition of $18.8 \mathrm{Cr}-15.8 \mathrm{Mo}-8.7 \mathrm{~W}-4.5 \mathrm{Ni}-3.2 \mathrm{Co}-2.4 \mathrm{Nb}-2.4 \mathrm{Ti}-0.7 \mathrm{Ta}-3.8 \mathrm{C}-$ 39.7B in atomic percent, Table 2. Surveys in the literature have also reported $\mathrm{M}_{3} \mathrm{~B}_{2}$ borides rich in $\mathrm{Cr}$, Mo and $\mathrm{W}[1,2,23,24]$. Mean equivalent radius and area fraction are tabulated versus sample condition in Table 2 for $\mathrm{M}_{3} \mathrm{~B}_{2}$ borides. These borides were most numerous in the as-extruded sample, as fine particles less than $0.4 \mu \mathrm{m}$ radius chiefly along the grain boundaries. The quantity observed along grain boundaries was greatly reduced by forging. Most borides dissolved after the supersolvus solution heat treatment, but widely scattered borides less than $0.5 \mu \mathrm{m}$ radius reappeared both within grains and at grain boundaries for long aging times at 760 and $843{ }^{\circ} \mathrm{C}$. The highest area fraction for each temperature was found at the longest aging time of $1,000 \mathrm{~h}$. The overall highest area fraction and average size of these borides was observed for $1,000 \mathrm{~h}$ aging at $927^{\circ} \mathrm{C}$ (Figure 5), where they grew into the largest minor phase particles found in this study, of $1.19 \mu \mathrm{m}$ mean radius.

$\underline{\sigma \text { Phase }}$

$\sigma$ phase particles had a tetragonal $\mathrm{P} 42 / \mathrm{mnm}$ crystal structure, with lattice parameters $\mathrm{a}=8.888 \AA, \mathrm{c}=4.593 \AA$ measured with XRD. Observed $\sigma$ precipitates were too small for composition measurements using the microprobe. Particles were separated by electrochemical phase extraction, and then analyzed by EDS in the SEM. This indicated a composition of $27.6 \mathrm{Co}-26.1 \mathrm{Cr}$ 14.2Mo-14.0W-11.7Ni-4.1Ta-2.4Ti in atomic percent, Table 3. The current measurements differ significantly from that reported in prior work, on superalloys having different overall compositions including lower Co content than LSHR [1, 2, 8, 9].

Mean equivalent radius and area fraction are shown versus sample condition in Table 2. $\sigma$ phase particles were found in a minority of examined cases, attaining a maximum area fraction of 0.00327 at $843{ }^{\circ} \mathrm{C}$ for $1,000 \mathrm{~h}$, (Figure 4). They appeared as irregular shapes at the grain boundaries, and seemed more elongated when nucleated in the grains. Some had distinct needle-like shapes. Several $\sigma$ phase particles were also found to be attached to small MC carbides. These $\sigma$ particles sometime appeared to have nucleated on the MC carbides, as this could require less energy. During aging at 843 and $927{ }^{\circ} \mathrm{C}$, these $\sigma$ particles appeared to precipitate first at the triple points of grain boundaries, and later within the grains. However, they were not observed after 1,000 h at $927^{\circ} \mathrm{C}$, indicating they were not stable at this temperature. 
Table 2. Measured minor phase mean equivalent radius $(\mathrm{R}$, in $\mathrm{nm}$ ) and fraction ( $\mathrm{f}$, in \%). IG and GB represent intragrain and grain boundary locations, respectively.

\begin{tabular}{|c|c|c|c|c|c|c|c|c|c|c|c|c|c|c|c|c|c|c|c|c|}
\hline \multirow{3}{*}{ Sample ID } & \multicolumn{6}{|c|}{$\mathrm{MC}$} & \multirow{2}{*}{\multicolumn{2}{|c|}{$\frac{\mathrm{M}_{23} \mathrm{C}_{6}}{\mathrm{~GB}}$}} & \multicolumn{6}{|c|}{$\mathrm{M}_{3} \mathrm{~B}_{2}$} & \\
\hline & \multicolumn{2}{|c|}{$\mathrm{IG}$} & \multicolumn{2}{|c|}{ GB } & \multicolumn{2}{|c|}{ All } & & & \multicolumn{2}{|r|}{$\mathrm{IG}$} & \multicolumn{2}{|c|}{ GB } & \multicolumn{2}{|c|}{ All } & \multicolumn{2}{|c|}{ IG } & \multicolumn{2}{|c|}{ GB } & \multicolumn{2}{|c|}{ All } \\
\hline & $R$ & 1 & $\mathrm{R}$ & $f$ & $\mathrm{R}$ & 1 & $\mathrm{R}$ & $f$ & $\mathrm{R}$ & $f$ & $R$ & $f$ & $R$ & $f$ & $\mathrm{R}$ & $f$ & $R$ & $f$ & $\mathrm{R}$ & $f$ \\
\hline$\overline{\mathrm{AF}-\mathrm{F}}$ & 151 & 0.060 & 164 & 0.040 & 156 & 100 & & & 276 & .034 & 359 & 0.023 & 299 & 057 & & & & - & $\overline{-1}$ & =- \\
\hline $\mathrm{FF}$ & 179 & i0 & 248 & \begin{tabular}{|l|}
0.035 \\
\end{tabular} & 186 & & & & & & & & & & & . & & - & - & - \\
\hline $\mathrm{EW}$ & 174 & 0 & 163 & \begin{tabular}{|l|}
0.014 \\
\end{tabular} & 173 & 164 & & & 178 & 00 & & & 178 & 0.002 & & 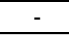 & - & - & - & - \\
\hline$\overline{F W}$ & 161 & $=$ & 177 & \begin{tabular}{|l|}
0.022 \\
\end{tabular} & 163 & 0.161 & 50 & & - & 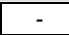 & & & - & & & - & - & - & - & - \\
\hline FW7 & 171 & 172 & 195 & \begin{tabular}{|l|}
0.017 \\
\end{tabular} & 173 & 0.189 & 104 & 5 & 364 & 0.033 & - & & 364 & 3 & & 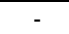 & - & - & - & - \\
\hline FW7 & 175 & 187 & 223 & 0.03 & 179 & 217 & 171 & 0.148 & 103 & 0.003 & 215 & 0.051 & 180 & 0.054 & - & - & - & 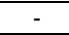 & - & - \\
\hline LFWE & 189 & 207 & 222 & 0.052 & 194 & 259 & 477 & 0.003 & $=$ & - & 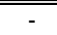 & 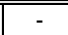 & $=$ & 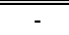 & - & & 77 & 0.001 & 77 & 0.001 \\
\hline FW & 95 & 191 & 223 & \begin{tabular}{|l|}
0.028 \\
\end{tabular} & 198 & $\mid 0.219$ & 144 & 0.095 & - & - & - & - & - & - & 163 & 0.012 & 216 & 0.045 & 196 & 0.057 \\
\hline FW8 & 191 & 0.169 & 262 & 0.015 & 194 & \begin{tabular}{|l|}
0.184 \\
\end{tabular} & 288 & 0.418 & 402 & 0.039 & 285 & 0.004 & 383 & 0.043 & 237 & \begin{tabular}{|l|l|}
0.184 \\
\end{tabular} & 333 & 0.143 & 264 & \begin{tabular}{|l|}
0.327 \\
\end{tabular} \\
\hline "FW927-10 & 192 & \begin{tabular}{l|l|}
0.143 \\
\end{tabular} & 207 & 0.054 & 195 & 0.197 & 1146 & 0.131 & 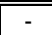 & (2- & $=$ & " - & "- & - & 161 & 0.006 & 175 & 0.053 & |174 & 0.059 \\
\hline \begin{tabular}{|l|} 
LFW927-99 \\
\end{tabular} & 177 & 0.099 & 268 & \begin{tabular}{|l|}
0.027 \\
\end{tabular} & 186 & $\mid 0.126$ & - & - & - & . & - & - & 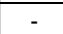 & - & - & - & 191 & 0.024 & 191 & 0.024 \\
\hline FW927-1k & \begin{tabular}{|l|}
192 \\
\end{tabular} & 0.248 & 239 & \begin{tabular}{|l|l|}
0.053 \\
\end{tabular} & 198 & 0.301 & - & - & 140 & 0.001 & 1186 & 0.827 & 1138 & 0.828 & & & & - & & - \\
\hline
\end{tabular}

Table 3. Experimentally measured versus thermodynamics predicted equilibrium minor phase compositions.

\begin{tabular}{|c|c|c|c|c|c|c|c|c|c|c|c|c|c|c|}
\hline Phase & Condition & Atomic $\%$ & Al & Co & $\mathrm{Cr}$ & Mo & $\mathrm{Nb}$ & $\mathrm{Ni}$ & $\mathrm{Ta}$ & $\mathrm{Ti}$ & W & C & B & $\mathrm{Zr}$ \\
\hline \multicolumn{3}{|c|}{ LSHR Alloy Compositions } & 7.4 & 20.4 & 14.0 & 1.7 & 0.9 & 49.2 & 0.5 & 4.2 & 1.4 & 0.14 & 0.15 & 0.03 \\
\hline \multirow{6}{*}{ MC } & \multirow{2}{*}{ LFW760-1k } & Mean & & & & & 12.0 & & 12.0 & 26.0 & & 50.0 & & \\
\hline & & StanDev & & & & & 1.4 & & 1.5 & 1.6 & & & & \\
\hline & \multicolumn{2}{|c|}{ Ni-Data $7\left(1199^{\circ} \mathrm{C}\right)$} & & & 0.2 & 0.1 & 12.9 & & 8.0 & 29.9 & 0.6 & 47.4 & & 0.9 \\
\hline & \multicolumn{2}{|c|}{ Ni-Data $7\left(760^{\circ} \mathrm{C}\right)$} & & & & 0.1 & 9.6 & & 8.8 & 0.5 & 0.1 & 49.5 & & 31.4 \\
\hline & \multicolumn{2}{|c|}{ PanNi 8 $\left(1199^{\circ} \mathrm{C}\right)$} & & & 5.0 & 1.1 & 6.1 & & 2.8 & 34.9 & 0.6 & 45.9 & & 3.6 \\
\hline & \multicolumn{2}{|c|}{ PanNi $8\left(978^{\circ} \mathrm{C}\right)$} & & & 4.7 & 1.3 & 8.9 & & 8.0 & 22.3 & 0.5 & 47.1 & & 7.3 \\
\hline \multirow{4}{*}{$\mathrm{M}_{23} \mathrm{C}_{6}$} & \multirow{2}{*}{ LFW760-1k } & Mean & & 20.6 & 33.0 & 5.4 & & 14.3 & & & 2.5 & 24.2 & & \\
\hline & & StanDev & & 1.6 & 3.8 & 0.6 & & 3.7 & & & 0.2 & 6.1 & & \\
\hline & \multicolumn{2}{|c|}{ Ni-Data $7\left(760^{\circ} \mathrm{C}\right)$} & & 5.6 & 59.8 & 9.5 & & 4.0 & & & 0.4 & 20.7 & & \\
\hline & \multicolumn{2}{|c|}{ PanNi $8\left(760^{\circ} \mathrm{C}\right)$} & & 5.6 & 70.3 & 1.9 & & 1.1 & & & 0.4 & 20.7 & & \\
\hline \multirow{4}{*}{$M_{3} B_{2}$} & \multirow{2}{*}{ LFW927-1k } & Mean & & 3.2 & 18.8 & 15.8 & 2.4 & 4.5 & 0.7 & 2.4 & $\begin{array}{lll}8.7 & & \end{array}$ & 3.8 & 39.7 & \\
\hline & & StanDev & & 0.4 & 1.6 & 1.7 & 0.4 & 0.1 & 0.1 & 0.2 & 1.0 & 1.3 & 5.8 & \\
\hline & \multicolumn{2}{|c|}{ Ni-Data $7\left(927^{\circ} \mathrm{C}\right)$} & & 0.4 & 20.8 & 37.5 & & 0.2 & & & 1.1 & & 40.0 & \\
\hline & \multicolumn{2}{|c|}{ PanNi $8\left(927^{\circ} \mathrm{C}\right)$} & & 1.7 & 19.9 & 36.6 & & 0.7 & & & 1.1 & & 40.0 & \\
\hline \multirow{4}{*}{ Sigma } & \multirow{2}{*}{ LFW843-1k } & Mean & & 27.6 & 26.1 & 14.2 & & 11.7 & 4.1 & 2.4 & 14.0 & & & \\
\hline & & StanDev & & 1.7 & 1.6 & 1.5 & & 0.6 & 1.4 & 0.7 & 1.5 & & & \\
\hline & \multirow{2}{*}{\multicolumn{2}{|c|}{ Ni-Data $7\left(843^{\circ} \mathrm{C}\right)$}} & & 28.8 & 48.0 & 10.0 & & 11.6 & & & 1.6 & & & \\
\hline & & & & 31.0 & 42.5 & 8.7 & & 7.0 & & & 10.8 & & & \\
\hline
\end{tabular}

Modeling

Equilibrium Modeling

Using the CALPHAD multicomponent thermodynamics database Ni-Data 7 [25] and Thermo-Calc software [26], equilibrium phase fraction predictions versus temperature are shown in Figure 7. The Ni-Data 7 database was shown in our earlier work [18] to have better agreement with experiments in predicting $\gamma / \gamma$ ' compositions and phase fractions than other databases. Note that this calculation was done using an effective alloy composition (second row of Table 3) obtained with a single equilibrium calculation at $1400{ }^{\circ} \mathrm{C}$, before other secondary solid phase formation, to remove components related to primary particles, which are alumina $\mathrm{M}_{2} \mathrm{O}_{3}(0.11 \%)$ and $\mathrm{M}(\mathrm{C}, \mathrm{N})(0.015 \%)$. This alters the alloy aluminum and titanium concentration only slightly. The obtained effective compositions are used in all subsequent model calculations. Furthermore, the results in Figure 7 were calculated without considering $\mu$ and $P$ phases, which were not observed experimentally. If they were considered in the calculation, $\mu$ phase (with atomic composition of $\left.\mathrm{Co}_{0.30} \mathrm{Mo}_{0.22} \mathrm{Cr}_{0.17} \mathrm{Ni}_{0.15} \mathrm{~W}_{0.14}\right)$ would become stable below $900{ }^{\circ} \mathrm{C}$ and reduce $\sigma$ phase stability.
The $\mathrm{MB}_{2}$ boride (basically $\mathrm{TiB}_{2}$ ) is predicted to be stable between 1070 to $1250{ }^{\circ} \mathrm{C}$, as shown in Figure 7. However, the $\mathrm{MB}_{2}$ phase was not found in any LSHR samples discussed earlier, probably due to a very low phase fraction and slow precipitation kinetics. The lower temperature $\mathrm{M}_{3} \mathrm{~B}_{2} \mathrm{Cr}$-Mo-rich borides are indeed found in the as-forged (LAF-Forged) samples (see Table 2), probably due to favorable precipitation kinetics over $\mathrm{MB}_{2}$ particles. The subsequent $1199{ }^{\circ} \mathrm{C}$ solution treatment eliminated almost all of $\mathrm{M}_{3} \mathrm{~B}_{2}$ particles found in the as-forged condition. However, this was not compatible with a separate equilibrium calculation suspending the $\mathrm{MB}_{2}$ phase, which suggested the stability of $\mathrm{M}_{3} \mathrm{~B}_{2}$ extends up to $1245^{\circ} \mathrm{C}$.

The $\mathrm{MC}$ and $\mathrm{M}_{23} \mathrm{C}_{6}$ carbides that were observed experimentally are predicted by equilibrium calculations in Figure 7 . MC carbides are predicted to exist at higher temperature, consistent with the experimental observation that MC exists in all LSHR samples. $\mathrm{M}_{23} \mathrm{C}_{6}$ is predicted to be stable below $850{ }^{\circ} \mathrm{C}$, which is qualitatively consistent with the experimental observations. Suspending $\sigma$ phase in the calculation increases the $\mathrm{M}_{23} \mathrm{C}_{6}$ solvus temperature by $5{ }^{\circ} \mathrm{C}$. Below $850{ }^{\circ} \mathrm{C}$, formation of $\mathrm{M}_{23} \mathrm{C}_{6}$ drives the dissolution of MC. This behavior is partially confirmed by 
experimental observations summarized in Table 2, where total volume fraction of $\mathrm{MC}$ is reduced in $843{ }^{\circ} \mathrm{C}$ aging. This MC dissolution process is predicted to release titanium, which results in a slight increase of $\gamma^{\prime}$ phase fraction.

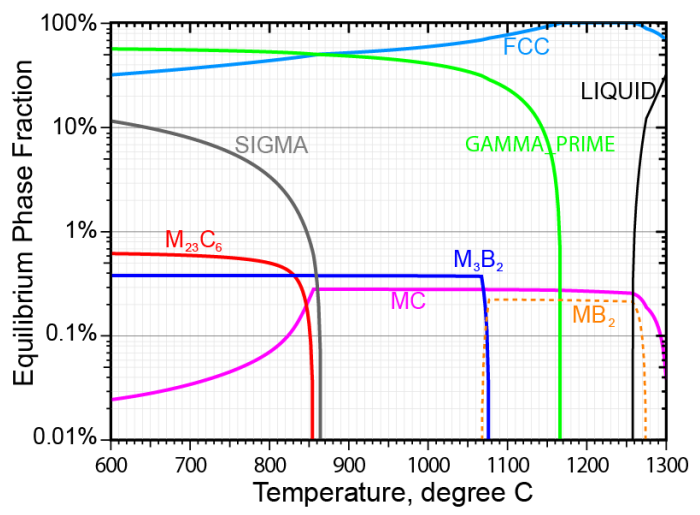

Figure 7. Predictions of equilibrium phase fraction versus temperature, using Thermo-Calc with Ni-Data 7 database.

Table 4. Predicted equilibrium phase fractions (contents) at the three aging temperatures.

\begin{tabular}{|c|c|c|c|}
\hline $\begin{array}{c}\text { Tempera- } \\
\text { ture, }{ }^{\circ} \mathrm{C}\end{array}$ & Phases & \multicolumn{2}{|c|}{ Phase Fractions \% } \\
\cline { 2 - 4 } & Ni-Data 7 & PanNi 8 \\
\hline \multirow{4}{*}{760} & $\gamma^{\prime}$ & 53.6 & 54.2 \\
\cline { 2 - 4 } & $\mathrm{MC}$ & 0.048 & - \\
\cline { 2 - 4 } & $\mathrm{M}_{23} \mathrm{C}_{6}$ & 0.55 & 0.65 \\
\cline { 2 - 4 } & $\mathrm{M}_{3} \mathrm{~B}_{2}$ & 0.38 & 0.38 \\
\cline { 2 - 4 } & Sigma & 6.8 & 8.7 \\
\hline \multirow{4}{*}{843} & $\gamma^{\prime}$ & 50.7 & 52.9 \\
\cline { 2 - 4 } & $\mathrm{MC}$ & 0.17 & - \\
\cline { 2 - 4 } & $\mathrm{M}_{23} \mathrm{C}_{6}$ & 0.25 & 0.61 \\
\cline { 2 - 4 } & $\mathrm{M}_{3} \mathrm{~B}_{2}$ & 0.38 & 0.38 \\
\cline { 2 - 4 } & $\mathrm{Sigma}_{4}$ & 1.3 & 6.3 \\
\hline \multirow{4}{*}{927} & $\gamma^{\prime}$ & 46.4 & 50.1 \\
\cline { 2 - 4 } & $\mathrm{MC}_{13}$ & 0.28 & - \\
\cline { 2 - 4 } & $\mathrm{M}_{23} \mathrm{C}_{6}$ & 0 & 0.56 \\
\cline { 2 - 4 } & $\mathrm{M}_{3} \mathrm{~B}_{2}$ & 0.38 & 0.37 \\
\cline { 2 - 4 } & $\mathrm{Sigma}_{2}$ & - & 3.5 \\
\hline
\end{tabular}

The $\sigma$ phase is predicted to be stable below $860{ }^{\circ} \mathrm{C}$ and can reach a significant area fraction below $800{ }^{\circ} \mathrm{C}$, according to equilibrium predictions. Omission of the boride phases in modeling increases $\sigma$ solvus temperature by $10^{\circ} \mathrm{C}$. The experimental observation of $\sigma$ phase at $843{ }^{\circ} \mathrm{C}$ aging confirms its stability, but at much lower observed area fractions due to slow precipitation kinetics. In 927 ${ }^{\circ} \mathrm{C}$ aging, however, the initial observation of $\sigma$ particles cannot be explained with the equilibrium predictions, though final disappearance at $1,000 \mathrm{~h}$ aging does support the thermodynamic predictions.

Table 4 summarizes the equilibrium phase fractions at the three aging temperatures predicted from both Ni-Data7/Thermo-Calc and PanNi8/Pandat, using the same assumptions discussed above. One major difference between the two databases is the transition temperature from $\mathrm{MC}$ to $\mathrm{M}_{23} \mathrm{C}_{6}$ carbides, where Ni-Data 7 estimates $850{ }^{\circ} \mathrm{C}$ and PanNi suggests a higher temperature of 984 ${ }^{\circ} \mathrm{C}$. Furthermore, PanNi 8 predicts $\sigma$ phase to be stable up to $1016^{\circ} \mathrm{C}$, much higher than that predicted by Ni-Data 7 database. However, from experimental data, it is not clear which database provides a better description of $\sigma$ phase stability.

Along with measured minor phase compositions of $1,000 \mathrm{~h}$ aging samples, the predicted compositions are also listed in Table 3 using both Ni-Data7/Thermo-Calc and PanNi8/Pandat at the corresponding aging temperatures. For MC carbides, since they pre-exist before the aging treatment, the predicted equilibrium compositions at the $1199{ }^{\circ} \mathrm{C}$ solution treatment are also shown in the table. The measured MC compositions in sample LFW760-1k can be largely explained by starting with the Ni-Data 7 predicted $1199{ }^{\circ} \mathrm{C}$ composition as a baseline, with small modifications towards that predicted at $760{ }^{\circ} \mathrm{C}$. Since $\mathrm{MC}$ is not stable at 760 ${ }^{\circ} \mathrm{C}$ by the PanNi 8 database, the MC composition is listed at its lowest stable temperature of $978{ }^{\circ} \mathrm{C}$. The PanNi 8 composition underestimates the $\mathrm{Nb}$ and $\mathrm{Ta}$ contents, while overestimating $\mathrm{Cr}$ and Ti contents.

For $\mathrm{M}_{23} \mathrm{C}_{6}$ carbides, there are large discrepancies of the predicted compositions from both databases versus the measured compositions. PanNi 8 predicts nearly pure $\mathrm{Cr}_{23} \mathrm{C}_{6}$ carbide composition, with only minor Co substitution for Cr. Ni-Data 7 predicts additional $\mathrm{Mo}$ and Ni substitution for $\mathrm{Cr}$. Experimentally measured compositions suggest much higher $\mathrm{Co}, \mathrm{Ni}$ and $\mathrm{W}$ contents, and a significantly lower $\mathrm{Cr}$ content.
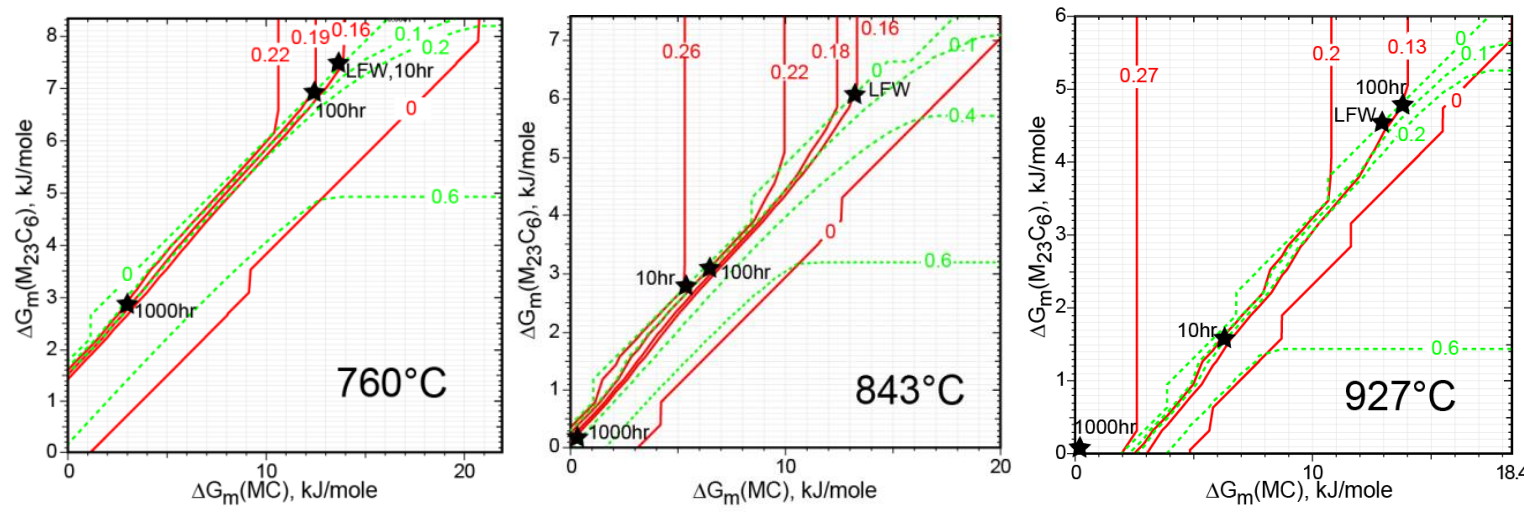

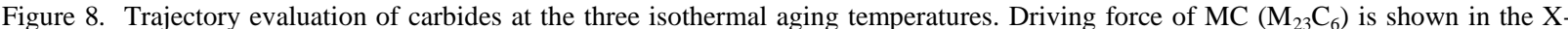
(Y-) axis. The stars represent the experimentally observed carbide fractions. The precipitation trajectory is formed by connecting the stars. The solid and dashed curves represent constant phase fractions curves of $\mathrm{MC}$ and $\mathrm{M}_{23} \mathrm{C}_{6}$ carbides, respectively. 
Predictions of $\mathrm{M}_{3} \mathrm{~B}_{2}$ compositions from both databases are very similar. However, both predictions overestimate Mo content, and underestimate $\mathrm{W}, \mathrm{Ni}, \mathrm{Nb}$ and $\mathrm{Ti}$. The predicted $\sigma$ phase compositions underpredict amounts of Mo, Ta and $\mathrm{W}$, and overpredict $\mathrm{Cr}$ content. PanNi 8 does predict a closer W content than does Ni-Data 7.

The discrepancies between model predictions and experimental observations could be caused by either the inaccuracy in thermodynamic databases or the observed phases not representing equilibrium conditions. If thermodynamic databases are indeed accurate, three explanations concerning non-equilibrium partitioning are listed below:

- Partial solute trapping and para-equilibrium constraint might explain the underestimation of particle compositions for slow diffusing elements. For example, the observed lower W partitioning ratio between $\gamma^{\prime}$ and $\gamma$ suggested partial solute trapping [18]. For minor phases studied here, observed lower Mo contents in $\mathrm{M}_{23} \mathrm{C}_{6}$ and $\mathrm{M}_{3} \mathrm{~B}_{2}$ might be driven by partial partitioning. However, the opposite effect is observed here for $\mathrm{W}$ in $\mathrm{M}_{23} \mathrm{C}_{6}, \mathrm{M}_{3} \mathrm{~B}_{2}$ and $\sigma$ particles, where actual $\mathrm{W}$ contents are higher than the equilibrium predictions ${ }^{1}$ from CALPHAD thermodynamic databases. This could suggest a need to refine the multicomponent databases.

- Formation of $\mathrm{M}_{23} \mathrm{C}_{6}, \mathrm{M}_{3} \mathrm{~B}_{2}$ and $\sigma$ particles mainly occurs on grain boundaries. The deviation of particle compositions can be driven by the enhanced diffusion on grain boundaries and multicomponent flux balance requirement.

- Compositional segregation to the grain boundaries was observed in Ni-base alloys. For example, substitutional elements, Mo, $\mathrm{Nb}$ and $\mathrm{W}$ were shown to partition to grain boundary $[27,28]$. This could lead to very different local compositions for the formation of grain boundary particles. This might also explain the initial precipitation of $\sigma$ and $\mathrm{M}_{23} \mathrm{C}_{6}$ at grain boundaries for $927{ }^{\circ} \mathrm{C}$ aging.

Carbide Precipitation Trajectory Analysis

The three plots in Figure 8 summarize the precipitation trajectory of $\mathrm{MC}$ and $\mathrm{M}_{23} \mathrm{C}_{6}$ carbides based on an unstable equilibrium fraction-supersaturation relationship where the precipitation driving force is balanced by capillary energy. This calculation was performed using Thermo-Calc with the Ni-Data 7 database, assuming $\gamma^{\prime}$ at equilibrium, and no $\mathrm{M}_{3} \mathrm{~B}_{2}$ and $\sigma$ phases present. This assumption is reasonable, as $\gamma^{\prime}$ precipitation kinetics is faster than for the carbides, while that for the boride and $\sigma$ phases appears to be even slower. The solid curves for MC and dashed curves for $\mathrm{M}_{23} \mathrm{C}_{6}$ carbides represent constant phase fractions within the X- (Y-) axis of driving forces of $\mathrm{MC}\left(\mathrm{M}_{23} \mathrm{C}_{6}\right)$. At the origins of the plot, driving forces for both carbides are zero, representing final equilibrium conditions. The star data points represent the experimentally observed total carbide fractions at different conditions. A smooth path would ideally be expected from the starting as-quenched (LFW) condition to the final 1,000 $\mathrm{h}$ aging condition, moving toward the origin. However, for both 843 and $927{ }^{\circ} \mathrm{C}$ aging treatments, the $100 \mathrm{~h}$ conditions seem to move away from equilibrium. Furthermore, due to slower kinetics, the condition of $760{ }^{\circ} \mathrm{C}$ for $1,000 \mathrm{~h}$ is still not close to

\footnotetext{
${ }^{1}$ Predicted $\mathrm{M}_{23} \mathrm{C}_{6}, \mathrm{M}_{3} \mathrm{~B}_{2}$ and $\sigma$ compositions under supersaturated unstable equilibrium condition still have the same discrepancy versus experimental measurement.
}

the equilibrium point. This information helps us understand the precipitation path along the thermodynamic supersaturation, and provides calibration input for the multiphase simulations discussed next.

\section{Precipitation Modeling for Carbides}

PrecipiCalc software has been successfully applied to capture the location-specific $\gamma^{\prime}$ microstructure's evolution in a $\gamma$ matrix for Ni-base disk alloys during non-isothermal processing $[17,18]$. In this work, PrecipiCalc software was used to simulate the concurrent $\gamma^{\prime}$, MC and $\mathrm{M}_{23} \mathrm{C}_{6}$ carbide microstructural evolution during isothermal aging, in order to assess the feasibility of modeling complex precipitation interactions and to identify potential model limits. Since PrecipiCalc utilizes CALPHAD thermodynamics and mobility databases, we can then also assess the impact of the discrepancies in phase fraction and compositions discussed earlier on the precipitation predictions.

In order to achieve a manageable simulation, the focus is placed on the carbides, assuming both boride and $\sigma$ phases can be suspended. This is reasonable as their formation kinetics is slower than carbides, as shown in Table 2. Even though $\mathrm{M}_{3} \mathrm{~B}_{2}$ achieves $0.8 \%$ phase content at grain boundaries in aging $927{ }^{\circ} \mathrm{C}$ for $1,000 \mathrm{~h}$, its impact on carbide compositions is still judged small. The $\gamma^{\prime}$ phase reaches equilibrium at a much faster rate than the carbides.

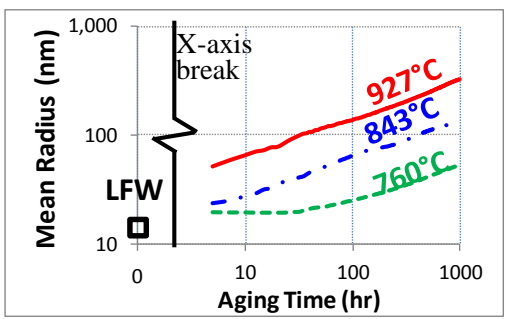

Figure 9. Predicted secondary $\gamma^{\prime}$ mean size evolution in LSHR from PrecipiCalc (curves) [29]. The predicted size in as-quench (LFW) sample is shown at $0 \mathrm{~h}$ aging time.

According to PrecipiCalc simulations, within one hour of aging above $760{ }^{\circ} \mathrm{C}, \gamma^{\prime}$ volume fraction should be at equilibrium. To further simplify the simulation, one could also consider removing the equilibrium $\gamma^{\prime}$ phase fraction and compositions to focus on the carbides' precipitation in the $\gamma$ matrix. However, in this isothermal aging study the $\gamma^{\prime}$ phase was included, using the parameters found in the previous study [18] including a starting microstructure of $14 \mathrm{~nm}$ mean radius and $47 \%$ phase content predicted from a separate PrecipiCalc simulation following the fast water quench (LFW) process. Results of predicted $\gamma^{\prime}$ size evolution at the three aging temperatures are shown in Figure 9, and further details can be found in [29]. After aging the grain boundary MC carbides constituted no more than a quarter of the total MC phase fraction, according to Table 2. Hence, MC carbides are modeled as intragrain particles with a homogeneous nucleation model, while later comparisons are made to total experimental $\mathrm{MC}$ size and fraction measurements. For $\mathrm{M}_{23} \mathrm{C}_{6}$ carbides, PrecipiCalc's classical heterogeneous grain boundary nucleation model for incoherent particles is used, with a $25 \mu \mathrm{m} \gamma$ grain size and a wetting angle of $33^{\circ}$, roughly representing the mid-value of the observed $\mathrm{M}_{23} \mathrm{C}_{6}$ morphology, which did often vary widely. PrecipiCalc's 3-dimensional volume diffusion- 
based growth model is utilized for both $\mathrm{MC}$ and $\mathrm{M}_{23} \mathrm{C}_{6}$ carbides. Applicability of this growth model to grain boundary $\mathrm{M}_{23} \mathrm{C}_{6}$ carbides will be discussed later. There is a prototype of PrecipiCalc with a revised grain boundary collector plate growth mechanism [31] which could also be relevant for $\mathrm{M}_{23} \mathrm{C}_{6}$, but the current implementation is limited to only one precipitate phase, so it is not used here.

The PrecipiCalc simulations discussed below rely on preprocessed PrecipiCalc parameters based on Ni-Data 7 and the NIST mobility database [30] using the unstable equilibrium approximation of the previous trajectory model. The preprocessed parameters help computational efficiency and also improve simulation stability. Once these parameters are generated, subsequent PrecipiCalc simulations no longer require CALPHAD free energy optimizations, which can be challenging for multi-phase precipitation simulation.

The starting microstructure at the beginning of the isothermal PrecipiCalc simulations is based on the experimental results for the LFW forged and water quenched sample. That is, (1) no $\mathrm{M}_{23} \mathrm{C}_{6}$ particles are assumed present; and (2) the MC particles are assumed to be normally distributed, have a mean radius ${ }^{2}$ of 173 $\mathrm{nm}$ and a standard deviation of $60 \mathrm{~nm}$. Total MC phase content is taken as $0.164 \%^{3}$.

In order to model the observed experimental data, calibration of a set of precipitation kinetics parameters was first necessary. The objective here was not to just model experimental results as accurately as possible, but to search for a minimum set of physical parameters to capture the observed behavior, in order to assess the sources of model inaccuracy. This calibration determined the following parameters.

- Carbide $/ \gamma$ interfacial energy was found to be $0.8 \mathrm{~J} / \mathrm{m}^{2}$ for both $\mathrm{MC}$ and $\mathrm{M}_{23} \mathrm{C}_{6}$ at all three temperatures. This higher than expected interfacial energy for intragrain $\mathrm{MC}$ carbides is probably necessary to account for the underestimation of slow diffusing Ta in MC (see Table 3).

- A diffusion scaling factor of 0.1 for $\mathrm{M}_{23} \mathrm{C}_{6}$ grain boundary carbides was needed and is justified as following. Though grain boundaries offer a faster diffusion path, volume diffusion of solute through the grains' microstructure containing a high fraction of $\gamma^{\prime}$ particles could dominate the formation rate. The reduction of diffusivity for $\mathrm{M}_{23} \mathrm{C}_{6}$ carbides is needed to correct the $\gamma^{\prime}$ diffusion barrier. In addition, the thermodynamic model underestimates the amount of the slow diffusing element $\mathrm{W}$ in $\mathrm{M}_{23} \mathrm{C}_{6}$ (Table 3 ), and results in an overestimated particle growth rate. Scaling down diffusion is thus needed to move toward the correct growth rate. This can also be related to an

\footnotetext{
${ }^{2}$ Small inaccuracy introduced here due to treating experimentally observed 2D particle sizes as 3D sizes to compare with PrecipiCalc simulations.

${ }^{3}$ The MC carbides in the as-quench sample are responsible for pinning the $\gamma$ matrix grain boundaries. With the measured MC size and phase content, the Zener pinning model, based on spatially uniform distribution of pinning particles, predicts a $\gamma$ grain size of $16 \mu \mathrm{m}$, under-estimating the measured grain size of $25 \mu \mathrm{m}$. This might suggest a spatially non-uniform MC carbide distribution. No abnormal grain growth was observed after the supersolvus heat treatment applied here.
}

incorrect use of a 3-dimensional growth model for grain boundary precipitation discussed later.

The results of the simulation are summarized and compared with experimental data in several plots within Figure 10. Time evolution of experimental mean radii, phase contents, and derived number densities are shown as discrete points based on experimental data in Table 2. PrecipiCalc results (labeled with "PpC") are shown as thick curves for mean size and fraction evolution. The microstructure of as-quench (LFW) sample is shown at the $0 \mathrm{~h}$ aging time.

Driven by the underlying thermodynamics, $\mathrm{MC}$ dissolution and $\mathrm{M}_{23} \mathrm{C}_{6}$ growth are predicted at 760 and $843{ }^{\circ} \mathrm{C}$, though there is no clear experimental evidence of $\mathrm{MC}$ dissolution at $760{ }^{\circ} \mathrm{C}$. Overall qualitative trends of carbide precipitation are captured by PrecipiCalc, but there are significant quantitative discrepancies. In addition to the incorrect carbide compositions from bulk thermodynamics discussed earlier, a large part of the discrepancies can be rationalized by the use of (1) the particle growth model based on 3-dimensional volume diffusion, (2) the single set of nucleation parameters on grain boundary, and (3) the mean field approximation where the carbides are distributed nonuniformly. The mean field assumption of PrecipiCalc considers all particles as surrounded with a mean far-field composition. Individual particles can interact with any other particles instantaneously. In reality, the carbides in LSHR depart from the mean field approximation. For example, grain boundary $\mathrm{M}_{23} \mathrm{C}_{6}$ carbides interact with only a small portion of $\mathrm{MC}$ carbides on or near the grain boundary. This also means the local surrounding compositions for the particles can strongly depend on the locations of carbides. As a result, use of the mean field assumption in this PrecipiCalc simulation could overestimate the communication between the carbides. This can explain the faster kinetics of dissolution and growth of carbides predicted by PrecipiCalc.

An important parameter of precipitate evolution during growth or coarsening is the time exponent for mean particle sizes. For 3 dimensional diffusional growth or coarsening of intragrain particles such as $\gamma^{\prime}$, the time exponent is $1 / 2$ or $1 / 3$. For grain boundary particles having no interactions with intragrain particles, experimental evidence and modeling have shown a lower coarsening time exponent, down to as low as $1 / 5$ [32]. If one includes interactions with intragrain particles, growth and coarsening of grain boundary particles can be slowed down to a time exponent of $1 / 5$ and $1 / 6$ [31], respectively. As shown in Figure 10 , the evolution of $\mathrm{M}_{23} \mathrm{C}_{6}$ mean size at 760 and $843{ }^{\circ} \mathrm{C}$, follows an exponent of $1 / 3.5$ and $1 / 3.7$, while PrecipiCalc follows a higher exponent. From the derived number density plots, it is shown that the experimental number density is increasing at 760 ${ }^{\circ} \mathrm{C}$ and following a time exponent of $1 / 3.5$, suggesting the nucleation process is ongoing up to $1,000 \mathrm{~h}$. At $843{ }^{\circ} \mathrm{C}$, nucleation of $\mathrm{M}_{23} \mathrm{C}_{6}$ seems to stop at $100 \mathrm{~h}$. Hence, actual $\mathrm{M}_{23} \mathrm{C}_{6}$ precipitation includes both nucleation and growth mechanisms. PrecipiCalc's nucleation kinetics is currently too fast and sharp, likely caused by the use of a single set of nucleation parameters, such as the wetting angle. In reality, a distributed and smooth nucleation behavior due to variation of grain boundary misorientation might be needed.

The mean sizes of experimental MC carbides are found to be very stable. By analyzing the data in Table 2, the time exponents of 
intragrain and grain boundary $\mathrm{MC}$ carbide mean radii are within $1 / 20$ to $1 / 60$. The slow kinetics of MC carbides is likely caused by their spatially non-uniform interaction with the $\mathrm{M}_{23} \mathrm{C}_{6}$ carbides and diffusion barriers related to the large volume fraction of $\gamma^{\prime}$ particles.

Most existing precipitation models focus on modeling single phase grain boundary or intragrain particles. The carbides in LSHR show complex precipitation behavior within a dual phase $\gamma$ $/ \gamma^{\prime}$ matrix, and suggest trends beyond current precipitation modeling capabilities. Note that these modeling challenges and limitations discussed above for carbides also apply to the $\sigma$ phase precipitation, Further model extensions appear necessary to fully describe the carbide precipitation behavior observed in LSHR Nibase superalloys. After refinement of these carbide precipitation simulations, the lessons learned can then be applied to include simultaneous precipitation of the $\sigma$ phase.

\section{Summary and Conclusions}

The predominant minor phases in disk superalloy LSHR were characterized after varied heat treatments. The results were used to assess existing model capabilities for predicting equilibrium states and precipitation for these multiple phases. It can be concluded from this work that:
1) Initial trials indicate joint precipitation of $\gamma^{\prime}$, MC carbide, and $\mathrm{M}_{23} \mathrm{C}_{6}$ carbides can be simulated using models such as PrecipiCalc.

2) Current model limitations are identified and additional model extensions have good potential to accurately describe precipitation of $\gamma^{\prime}$ and carbides during aging heat treatments.

3) This may require modifications and extensions to current treatments of fundamental multicomponent thermodynamics and multi-phase precipitation models. In particular, the focus should be placed on elemental partitioning, grain boundary diffusion, segregation and distributive nucleation, and the interaction of spatially non-uniform particles.

\section{Acknowledgement}

This work was supported by the NASA Aviation Safety Program and Glenn Research Center (GRC) under Contract No. NNC07CB01C. The authors acknowledge John Gayda of NASA GRC for project collaboration, Jeff Simmons and Chris Woodward of the Air Force Research Laboratory for serving as science advisors of this program, David Furrer, Robert Goetz, Rob Mitchell and Mark Hardy of Rolls-Royce Corporation for serving as industrial advisors of this program, and Carelyn Campbell of NIST for providing the mobility database.
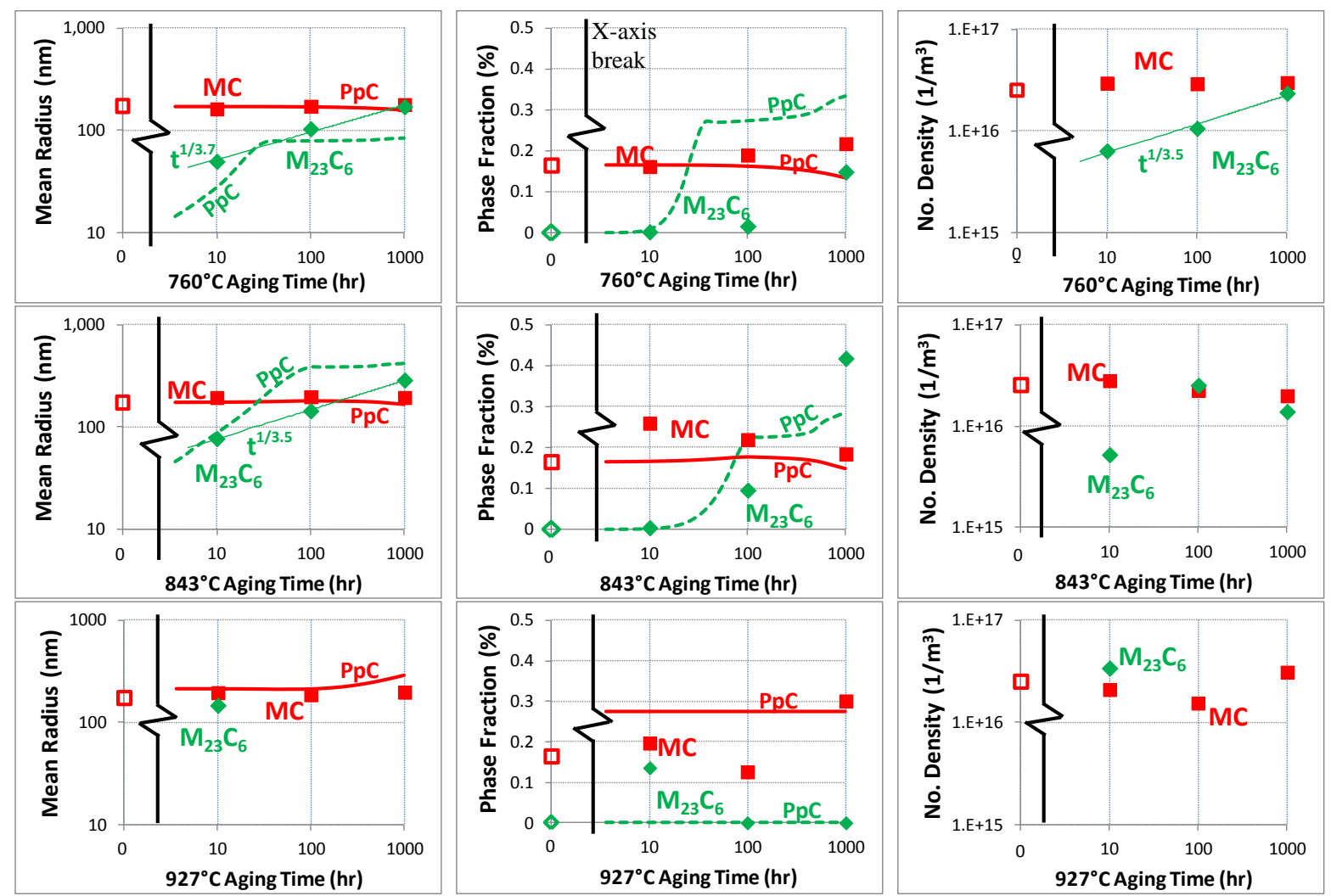

Figure 10. Comparison of LSHR carbide microstructure evolution between experiments (points) and PrecipiCalc predictions (thick curves labeled with "PpC"). Both MC (squares and solid curves) and $\mathrm{M}_{23} \mathrm{C}_{6}$ (diamonds and dash curves) are shown. The as-quenched carbide microstructure is shown at $0 \mathrm{~h}$ with hollow symbols. Thin lines represent power law fits to the experimental data, suggesting the time evolution exponent. The number density is calculated as phase fraction divided by particle volume at mean size. 


\section{References}

1. C. T. Sims, N. S. Stoloff, W. C. Hagel, Superalloys II, John Wiley \& Sons, Inc., New York, 1987, pp. 91-133.

2. R. C. Reed, The Superalloys, Cambridge University Press, 2006, pp. 35-54

3. R. F. Decker, "Strengthening Mechanismss in Nickel-Base Superalloys", Steel Strengthening Mechanisms Symposium, Climax Molybdenum Company, 1969.

4. S. Floreen, J. M. Davidson, "The Effects of B and $\mathrm{Zr}$ on the Creep and Fatigue Crack Growth Behavior of a Ni-base Superalloy", Met Trans. A, V. 14A, 1983, pp. 895-901.

5. T. J. Garosshen, T. D. Tillman, G. P. McCarthy, "Effects of $\mathrm{B}, \mathrm{C}$, and $\mathrm{Zr}$ on the Structure and Properties of a P/M Nickel Base Superalloy", Met. Trans. A, V. 18A, 1987, pp. 69-77.

6. E. S. Huron, K. R. Bain, D. P. Mourer, J. J. Schirra, P. L. Reynolds, E. E. Montero, "The Influence of Grain Boundary Elements on Properties and Microstructures of P/M Nickel Base Superalloys", Superalloys 2004, ed. K. A. Green, T. M. Polock, H. Harada, T. E. Howson, R. C. Reed, J. J. Schirra, S. Walston, TMS, Warrendale, PA, 2004, pp. 73-81.

7. E. L. Raymond, R. D. Kissinger, A. J. Paxson, E. S. Huron, "Method for Forming a Nickel-base Superalloy Having Improved Resistance to Abnormal Grain Growth", U.S. Patent 5,584,947, U.S. Patent Office, 1996.

8. R. L. Dreshfield, R. Ashbrook, "Sigma Phase Formation and Its Effect on Stress Rupture Properties of IN-100", NASA TND-5185, Washington, D.C., April 1965.

9. R. C. Reed, M. P. Jackson, Y. S. Na, "Characterization and Modeling of the Precipitation of the Sigma Phase in Udimet 720 and Udimet 720LI", Met. Trans. A, V. 30A, 1999, pp. 521-533.

10. H. Murphy, C. T. Sims, "Phacomp Revisited", Symp. On Structural Stability in Superalloys, ASTM-ASME, 1968, pp. 47-66.

11. M. Moringa, N. Yukawa, H. Ezaki, H. Adachi, "New PHACOMP and Its Applications to Alloy Design (Phase Computation)", Superalloys 1984, ed. M. Gell, C. S. Kortovich, R. H. Bricknell, W. B. Kent, J. F. Radavich, The Metallurgical Society of AIME, 1984, pp. 523-532.

12. L. Kaufman and H. Bernstein, Computer Calculation of Phase Diagrams, Academic Press, New York, 1970

13. http://www.calphad.org/

14. J.O. Andersson, T. Helander., L. Höglund, P.F. Shi, and B. Sundman, "Thermo-Calc and DICTRA, Computational tools for Materials Science," Calphad, 26, 273-312.

15. N. Saunders, Z. Guo, X. Li, A. P. Miodownik, J.-P. Schille, "Modelling The Material Properties and Behavior of $\mathrm{Ni}$ Based Superalloys," Superalloys 2004, ed. K.A. Green, T.M Pollock, H. Harada, T.E. Howson, R.C. Reed, J.J. Schirra, and S. Walston. The Minerals, Metals, and Materials Society, Warrendale, PA, 2004, pp. 849-858.

16. W. Cao, S.-L. Chen, F. Zhang, K. Wu, Y. Yang, Y. A. Chang, R. Schmid-Fetzer, W. A. Oates, "PANDAT Software with PanEngine, PanOptimizer and PanPrecipitation for Multi-Component Phase Diagram Calculation and Materials Property Simulation", Calphad, V. 33(2), 2009, pp. 328-342.

17. H.-J. Jou, P. Voorhees and G.B. Olson, "Computer Simulations for the Prediction of Microstructure/Property Variation in Aeroturbine Disks," Superalloys 2004, ed. K.A Green, T.M. Pollock, H. Harada, T.E. Howson, R.C. Reed,
J.J. Schirra, and S, Walston, The Minerals, Metals, \& Materials Society, 2004, pp. 877-886.

18. G.B. Olson, H.-J. Jou, J. Jung, J.T. Sebastian, A. Misra, I. Locci and D. Hull, "Precipitation Model Validation in 3rd Generation Aeroturbine Disc Alloys," Superalloys 2008, ed. R.C. Reed, K.A. Green, P. Caron, T.P. Gabb, M.G. Fahrmann, E.S. Huron, and S.A. Woodward, The Minerals, Metals, \& Materials Society, 2008, pp. 923-932.

19. http://www.thermocalc.com/TC-PRISMA.htm

20. J.-C. Zhao, M. F. Henry, "The Thermodynamic Prediction of Phase Stability in Multicomponent Superalloys", Journal of Metals, V. 54 (1), 2002, pp. 37-41.

21. Integrated Computational Materials Engineering: A Transformational Discipline for Improved Competitiveness and National Security, Committee on Integrated Computational Materials Engineering, National Research Council, 2008

22. T. P. Gabb, A. Garg, D. R. Miller, C. K. Sudbrack, D. R. Hull, D. Johnson, R. B. Rogers, J. Gayda, S. L. Semiatin, "Formation of Minor Phases in a Nickel-based Superalloy", NASA/TM-2012-217604, Washington, D.C., 2012.

23. T. P. Gabb, A. Garg, D. L. Ellis, "Microstructrual Evaluations of Baseline HSR/EPM Disk Alloys", NASA/TM-2004-213123, Washington, D.C., 2004.

24. S. T. Wlodek, M. Kelly, D. A. Alden, "The Structure of Rene' 88DT", Superalloys 1996, ed. R. D. Kissinger, D. J. Deye, D. L. Anton, A. D. Cetel, M. V. Nathal, T. M. Pollock, D. A. Woodford, TMS, Warrendale, PA, 1996, pp. 129-136.

25. N. Saunders, M. Fahrmann and C.J. Small, "The Application of CALPHAD Calculations to Ni-Based Superalloys," Superalloys 2000, eds. K.A. Green, T.M. Pollock and R.D. Kissinger, (TMS, Warrendale, 2000), 803

26. http://www.thermocalc.com/Products/TCC.html

27. D.H. Ping, Y.F. Gu, C.Y. Cui, H. Harada, "Grain Boundary Segregation in a Ni-Fe-based (Alloy 718) Superalloy," Materials Science and Engineering A 456 (2007) 99-102.

28. A.J. Detor, C. A. Schuh, "Grain Boundary Segregation, Chemical Ordering and Stability of Nanocrystalline Alloys: Atomistic Computer Simulations in the Ni-W System," Acta Materialia 55 (2007) 4221-4232

29. H.-J. Jou, "Microstructure Modeling of 3rd Generation Disk Alloys", NASA/CR-2010-216229, Washington, D.C., 2010.

30. C.E. Campbell, W.J. Boettinger, and U.R. Kattner, "Development of a diffusion mobility database for Ni-based superalloys," Acta Materialia, 50 (2002) 775-792.

31. QuesTek internal work for modeling grain boundary $\eta$ precipitation of AA7xxx alloys, with and without the presence of intragrain precipitates.

32. E. Kozeschnik, J. Svoboda, R. Radis and F.D. Fischer, "Mean-field Model for the Growth and Coarsening of Stoichiometric Precipitates at Grain Boundaries," Modelling Simul. Mater. Sci. Eng. 18 (2010) 015011. 